\title{
Unifying National Income Inequality and Regional Economic Divergence
}

\author{
Robert Manduca
}

Abstract: After more than a century of convergence, the economic fortunes of rich and poor regions of the United States have diverged dramatically since 1980. The richest cities now have per capita incomes almost $40 \%$ greater than the nation as a whole, while the poorest ones have incomes $25 \%$ smaller. In this paper I use counterfactual simulations based on Census microdata to understand the dynamics of regional divergence. I first show that regional divergence has largely resulted from the richest people and places pulling away from the rest of the country. I then estimate the relative contributions to regional divergence of two major socioeconomic trends of the last 40 years: the sorting of people across metro areas by income level and the national rise in income inequality. I show that the national rise in income inequality is sufficient on its own to account for more than half of the observed divergence across regions, while income sorting on its own accounts for less than a quarter. The major driver of regional economic divergence is national-level income dispersion that has exacerbated preexisting spatial inequalities. 
Regions of the United States are pulling apart. After more than a century during which the poorest parts of the country caught up economically to the rest, since 1980 it is the highestincome regions - typically defined as states or metro areas-whose incomes have grown the fastest (Amos 2014; Barro and Sala-i-Martin 1992; Ganong and Shoag 2017). In 1980, the richest $10 \%$ of metro areas had per capita incomes about $20 \%$ larger than the national mean. Today the difference is $37 \%$. The single richest major city in 1975 was not quite $40 \%$ richer than the nation as a whole, while San Francisco today is almost $60 \%$ richer. Meanwhile, the proportion of the country living in metros with per capita incomes below $90 \%$ of the national average has increased from about a quarter to more than a third.

Regional income divergence is a major economic and social challenge for the United States. It makes formulating federal economic policy difficult, since one federal budget and interest rate must meet the needs of rich and poor regions simultaneously (Schleicher 2017). It may also contribute to the country's large regional variation in upward mobility rates (Chetty et al. 2014), since the economic conditions of children's communities strongly affect their prospects in life (Chetty and Hendren 2016; Sampson 2012; Sharkey and Faber 2014; Wilson 1987). More fundamentally, divergence contributes to a lack of social and political cohesion, as the material interests of different parts of the country diverge and their residents come to see themselves as having less and less in common (Beramendi 2007, 2012).

The aim of this paper is to determine the relative importance of individual and macrolevel processes in driving the regional income divergence observed over the last few decades. Previous explanations of divergence have focused on individual location choices that have resulted in the spatial concentration of human capital. Since the 1980s workers have become increasingly sorted across cities by education level (Moretti 2012). Rural towns have seen many 
of their brightest students leave for good (Carr and Kefalas 2009), while a set of major metro areas has claimed an increasing share of the nation's college graduates (Berry and Glaeser 2005). Scholars differ as to whether these changes in the geography of human capital are due to differences in labor demand (Diamond 2016; Kemeny and Storper 2012), limitations on housing supply (Ganong and Shoag 2017; Gyourko, Mayer, and Sinai 2013), or varying access to lifestyle amenities (Florida 2002; Glaeser, Kolko, and Saiz 2001).

Nevertheless, most previous accounts suggest or imply that the diverging fortunes of regions are primarily a consequence of changes in where workers of different skill levels choose to live. Overall patterns of regional divergence are interpreted as resulting from the aggregation of millions of individual location decisions. Proposed policy solutions attempt to alter the geographical distribution of skill by changing the calculus behind those decisions, whether by increasing the attractiveness of regions to high skilled workers (Florida 2002) or making it less costly for lower-income people to move to wealthy areas (Avent 2011; Yglesias 2012).

\section{An Alternative Perspective}

Regional divergence could equally result from the spatially disparate effects of a single national-level trend, refracted through already existing social structures in a way that produces concentrated effects. As human capital was becoming more spatially concentrated between 1980 and 2015, the distribution of economic resources was also becoming much more skewed. The share of national pre-tax income going to the richest $1 \%$ of Americans has almost doubled since 1975, while the incomes of the poorer half of the population have hardly budged in real terms (Piketty, Saez, and Zucman 2016). Most proposed explanations for rising inequality attribute it

primarily to national or global changes in technology (e.g. Autor, Levy, and Murnane 2003) and 
institutions (e.g. Hacker and Pierson 2010). These changes are typically described in aspatial terms. But because different income groups are unevenly distributed across the country, national changes will have spatially uneven effects. Like a wave that washes over an uneven landscape, leaving behind deep pools in some areas and shallow puddles in others, the same macro-level social trend can have very different impacts on different areas depending on how people are distributed across space.

Previous research has documented this general phenomenon in settings including the concentration of poverty (Massey 1990), incarceration (Sampson and Loeffler 2010), and deindustrialization (Autor, Dorn, and Hanson 2013). The intuition behind it was perhaps best captured by Massey (1990), who used simulations to show that the combination of racial and class segregation would concentrate the effects of a national economic downturn into specific neighborhoods. He showed that in a hypothetical city completely segregated by race and class, a 2.5 percentage point increase in the overall poverty rate would coincide with a 20 percentage point increase in the poverty rate of poor black neighborhoods. When places are highly stratified, small macro shifts can have immense local effects.

In the spirit of Massey, this paper uses simulations to investigate the relative importance of income sorting and income inequality as drivers of regional economic divergence. In doing so, it applies insights from urban sociology to the study of subnational regions, a geographic scale too often neglected by sociologists (Lobao and Hooks 2007). After documenting the extent to which regional disparities have widened over the past 40 years, I use counterfactual simulations to show that this divergence is almost entirely driven by the richest people and places: there has been very little regional divergence, at least as typically measured, among the poorest $90 \%$ of the population. Further simulations show that roughly a quarter of the total divergence results solely 
from changes in the spatial distribution of workers, while a larger proportion is attributable to increased income inequality. Absent the rise in inequality, the observed changes in the geography of workers would have resulted in only about $23 \%$ as much divergence as actually occurred. In contrast, the rise in income inequality of the last 40 years would have produced $53 \%$ of the observed divergence even if there had been no income sorting whatsoever. Income sorting has played a role in driving regional divergence, but income inequality has played a larger one. ${ }^{1}$

More broadly, this paper highlights how spatial inequality of any type can exacerbate itself. The presence of some initial amount of inequality across geographic areas will make those areas differentially susceptible to macro trends in ways that will often cause their fortunes to further diverge. This dynamic is not unique to space: it can occur in any instance where people are sorted unevenly across units - that is, in any social structure with a strong correlation between graduated and nominal parameters (Blau 1974, 1977). Once that correlation is established, the exacerbation of inequality along the graduated parameter will further increase the distance between nominal groups. The spatial implications of this are particularly counterintuitive, because it means that changes in spatial patterns do not have to be driven by an explicitly geographic process. Since all social processes are spatially situated, even seemingly aspatial developments will often have distinct spatial profiles.

\section{PREVIOUS RESEARCH}

\section{Neoclassical Economic Theory and Trends in Regional Income Divergence}

Neoclassical economic theory predicts that the free movement of people and capital will lead to economic convergence across regions over time (Barro and Sala-i-Martin 1992). In the absence of barriers to movement, workers and investors are expected to flock to prosperous 
areas, which will compete down wages and investment returns there while lessening competition in the places they leave. This migration is predicted to continue until income (or perhaps utility) is even across space (Glaeser and Gottlieb 2009).

Such a convergence was observed in the United States from the late 1800s until the 1980s (Barro and Sala-i-Martin 1990, 1991). Since then, however, regional convergence has stalled. The total amount of cross-sectional variation across states began increasing in the late 1970s (Amos 1989; Fan and Casetti 1994), and cross-sectional variation across metropolitan areas increased substantially from 1964 to 2009 (Hsieh and Moretti 2017). Initially poor states grew faster than rich ones from the late 1800s until the mid-1970s (Barro and Sala-i-Martin 1991, 1992), but since then there has been little relationship between initial income and subsequent growth, either at the state (Ganong and Shoag 2013) or metro (Berry and Glaeser 2005) level. Among college-educated workers wages in initially prosperous cities grew faster than wages in initially poor ones from 1980 to 2010 (Giannone 2017).

\section{Human Capital Concentration as a Cause of Regional Economic Divergence}

Most scholarly attempts to explain diverging regional fortunes have emphasized the increasing geographical concentration of college-educated workers. Beginning in 1980, cities began to polarize in their educational profiles. In a process that has been termed the "Great Divergence" (Moretti 2012), cities that already had large numbers of highly educated workers attracted or trained still more, while those that had fewer to start with failed to keep up (Berry and Glaeser 2005; Giannone 2017). Many rural towns experienced a brain drain as their brightest students left, rarely to return (Carr and Kefalas 2009). 
One set of explanations for this concentration focuses on attraction of skilled workers to certain places. Some researchers argue that the concentration is driven by labor demand (Diamond 2016; Storper and Scott 2009), while others emphasize the role of lifestyle considerations, particularly for the most well-compensated individuals (Clark et al. 2002; Dahl and Sorenson 2010; Florida 2002; Glaeser et al. 2001). Further accounts stress the role of networks and social norms that funnel elite college graduates to specific opportunities in specific places (Binder, Davis, and Bloom 2015; Author 2017).

A second set of explanations emphasizes barriers that limit the ability of people to leave economically struggling areas and enter thriving ones. Constraints on housing supply, whether natural impediments like oceans and mountains or policy choices like zoning regulations, drive up the cost of living in desirable areas and make it difficult for the less affluent to live there (Ganong and Shoag 2017; Gyourko et al. 2013). There are also numerous legal barriers to interstate migration, including state occupational licensing schemes, public benefit systems, and property laws (Schleicher 2017). Constraints on migration slow the equilibration of the economy, preventing workers from leaving low-wage areas to move to high-wage ones. In this way they contribute to inequality among both people and regions.

The common thread of these previous explanations for regional divergence is the geographic sorting of people by skill or income. On some level, they all argue that regional fortunes are diverging because high income workers increasingly live in one set of cities while low income workers live in another. As this pattern has increased over time the economic prospects of these two types of cities have drifted apart.

Human capital concentration is indeed a major socioeconomic trend of the past 40 years, and a departure from earlier periods (Giannone 2017). But its significance as a driver of 
economic divergence is less clear. The mere presence of regional income differences requires that people of different incomes be unevenly distributed across space. An increase in income inequality nationwide may therefore be sufficient on its own to increase inequality across regions.

\section{Increasing National Income Inequality}

The rise in income inequality is perhaps the most momentous social and economic change of the past 40 years. Since 1975 the vast majority of economic growth has been captured by the richest people in the country, while incomes for the poorer half have stagnated. The top $0.1 \%$ of the country now earns roughly as much each year as the bottom $50 \%$ (Piketty et al. 2016). Importantly, inequality rose simultaneously within race, age, gender, and education groups (Lemieux 2006; McCall 2000), suggesting that it is best understood as a macro trend rather than a combination of various stratification processes.

Theories abound as to why the United States has become so unequal. The canonical explanation in the economics literature is skill-biased technological change, which in its most common formulation posits that technologies developed in recent decades have increased the demand for college-educated workers (Autor, Katz, and Krueger 1998; Autor et al. 2003). Other explanations argue instead that rising income inequality stems from institutional changesperhaps driven by the rise of the business lobby in the 1970s (Hacker and Pierson 2010) — that have eroded protections for workers at the bottom of the income distribution while maintaining or increasing protections for those at the top (Stiglitz 2015; Weeden and Grusky 2014). Institutional changes that have worsened the position of the working class and poor include the declining minimum wage (Lee 1999), decreasing levels of unionization (Western and Rosenfeld 
2011), and the reduction of trade barriers (Autor, Dorn, and Hanson 2016). The position of those at the top has been strengthened through more widespread occupational licensing (Weeden 2002), the increasing market power of large firms (Autor et al. 2017; Comanor and Smiley 1975), and lower top marginal tax rates (Piketty, Saez, and Stantcheva 2014).

Most proposed explanations for the rise in income inequality operate primarily at the national or global scale, (although state-level institutions and policies play a role—see Moller, Alderson, and Nielsen, 2009). Nonetheless, there is reason to expect that their effects will be felt differently in different places. Because people live in places, and because people are unevenly distributed with respect to income or any other social characteristic, changes in the distribution of income among people will necessarily change the distribution of income across places. This underappreciated truism forms the starting point for my analysis.

\section{The Geographically Uneven Effects of Macro-Level Social Trends}

Because different types of people are clustered in different places, macro-level policy or social changes frequently have very different effects on different regions or neighborhoods. Possibly the most famous demonstration of this is the proof by simulation that segregation by race and class will magnify the effects of economic downturns, creating large increases in the poverty rates of specific neighborhoods from even relatively small national fluctuations (Massey 1990). This dynamic was felt in the Great Recession, when subprime loans and the associated foreclosures were disproportionately concentrated in segregated minority neighborhoods (Hwang, Hankinson, and Brown 2015; Hyra et al. 2013). The rise in mass incarceration since the 1970s has similarly fallen disproportionately on a few specific neighborhoods of concentrated disadvantage (Sampson and Loeffler 2010), and even on a small number of "Million Dollar 
Blocks" - single city blocks where more than $\$ 1$ million is spent incarcerating residents each year (Kurgan et al. 2012). Although the policy choices leading to rising incarceration rates were made at the national, state, or even city level, the effects have been concentrated in particular neighborhoods.

At the regional level, most directly analogous to the present study are papers that have documented the localized labor market effects of macroeconomic trends. Increasing automation and trade with China are not inherently spatial processes, but their effects have been felt unevenly across the United States (Autor and Dorn 2013; Autor et al. 2013; Autor et al. 2016). Changes in industry market concentration have also been hypothesized to have effects that vary across regions (Longman 2015; Urzúa 2013).

These examples are cases where existing spatial heterogeneity meant that one national policy choice or economic shock had extreme geographic variation in its effects. Residents of million dollar blocks didn't necessarily change their behavior in response to the prison boom-if anything, crime rates went down as mass incarceration was reaching its apex. Rather, the policy choice to increase incarceration rates interacted with the existing social and spatial patterns of life and crime, with the perhaps unforeseen result of overwhelmingly targeting a small number of places. The question for the current paper is whether the national trend of increased income inequality has had a similarly varied spatial profile.

\section{Studying Spatial Processes at Multiple Scales: Insights from Urban Sociology}

Like this paper, research in urban sociology has had to determine whether observed spatial patterns are primarily the aggregated result of individual choices or the required outcome of structural forces. In the literature on urban poverty, a core question has been whether 
concentrated poverty results more from the selective migration of middle class African Americans (e.g. Quillian 1999; Wilson 1987) or from metro-wide racial and class segregation, (e.g. Massey 1990; Massey, Gross, and Shibuya 1994). Recent work suggests that the exposure of any individual to concentrated poverty is shaped more by the racial and class structure of their metropolitan area than by their own residential mobility (Sampson, Schachner, and Mare 2017; Sampson and Sharkey 2008). An important conclusion of this literature is that whether racial desegregation results in increases or decreases in concentrated poverty depends on the preexisting spatial distribution of poor and non-poor members of different races (Quillian 2012). Conditions in most US metros are such that racial segregation does contribute to concentrated poverty, but that is an empirical finding and not a theoretical requirement. The present study is analogous: either income sorting or income inequality on its own could be sufficient to explain regional divergence. Which trend is more important is an empirical question that depends on the initial and current distributions of population and income.

A separate debate in urban sociology has asked whether metropolitan segregation itself results more from the interplay of individual preferences and endowments (Clark 1991; Schelling 1971) or collective — often political — actions that limit who can live where (Logan 1978). Examples of the latter include restrictive covenants (Gotham 2000), exclusionary zoning (Rothwell and Massey 2009), and straightforward physical intimidation (Meyer 2001). Studies of within-metro income segregation have shown both that neighborhoods have polarized by income (Bischoff and Reardon 2014, Figure 1) and that families are more sorted by income across neighborhoods and school districts than they used to be (Bischoff and Reardon 2014; Owens 2016; Reardon and Bischoff 2011, 2016). 
In both of these subfields of urban sociology, major advances have come from the use of simulation models to play out the spatial effects of changes in individual preferences, population structure, or income levels (Bruch 2014; Bruch and Mare 2006; Massey 1990; Schelling 1971). Because spatial patterns result from complicated interactions at many different scales, the effects of any particular change are often counterintuitive and best isolated through simulations that hold all other factors constant. That is the method that I employ here.

\section{CONCEPTUAL SEPARATION OF INCOME SORTING AND INCOME INEQUALITY}

Scholars of stratification often find it helpful to analytically separate the allocation of people into jobs or positions from the assignment of reward packages to those positions (Weeden 2002). A similar distinction can be made between the allocation of ranks in the national income distribution to cities, what I am calling income sorting, ${ }^{2}$ and the assignment of rewards to those ranks - that is, the level of income inequality. To illustrate how both sorting and inequality can contribute to regional divergence, consider the hypothetical country shown in Figure 1. The country has two cities and a mean national income of $\$ 10$. At start, in panel A, incomes in City A are symmetrically distributed around a mean of $\$ 8$, while incomes in City B are similarly distributed around a mean of $\$ 12$.

[Figure 1 about here]

Panel B shows the income distributions of the two cities after an episode of income sorting. The overall distribution for the country has stayed the same, but people have moved such that high-income residents overwhelmingly live in City B while low-income residents now live 
in City A. In the language of Weeden, the allocation of positions-here ranks in the national income distribution - across cities has changed, but the income associated with each position has not. ${ }^{3}$ As is clear in the graph, this sorting substantially reduces the amount of overlap in the two distributions. It also leads to divergence in the mean incomes of the two cities, with the mean income in City A falling to $\$ 7.40$ and the mean income in City B rising to $\$ 12.60$.

Panel C shows what would happen to the two cities with no sorting but an increase in income inequality at the national level —if the set of positions in each city does not change but the rewards at each position do. This stretching of the national income distribution is implemented by subtracting $\$ 1$ from the income of everyone in the country making less than $\$ 10$ and adding $\$ 1$ to the income of everyone earning more than $\$ 10$. The mean national income stays at $\$ 10$, but incomes are now more polarized. Here the two distributions show more overlap than in panel B, but their peaks are further apart than in either of the previous two panels. Mean incomes diverge by an amount comparable to panel B, with the mean income of City A falling to $\$ 7.50$ and that of City B rising to $\$ 12.50$. Importantly, a study that looked only at mean incomes would have difficulty distinguishing the sorting process in panel B from the stretching process in panel $\mathrm{C}$, even though the mechanisms underlying the two cases and the resulting city income distributions are quite different.

Of course, income sorting and income inequality can increase at the same time, with even greater effects on regional income disparities. This is shown in panel D, which implements the changes from panels B and C simultaneously. In this case, interaction between sorting and inequality creates divergence greater than in the previous two scenarios combined. Because the rich are both richer and more geographically concentrated, they pull the incomes of City B up much more than they do in either previous scenario. The same process happens in City A with 
the poor, with the result that the mean income of City A falls to $\$ 6.50$ while that of City B rises to $\$ 13.50$.

The relative importance of these two mechanisms is an empirical question that depends on the initial distribution of positions across cities and the amount of change in both the location and rewards of each position. This is the question I seek to answer here.

\section{DATA AND METHODS}

In this paper I combine descriptive analysis of trends in various measures of regional economic divergence within the United States from 1975-2015 with counterfactual simulations to estimate the relative importance of income sorting and income inequality in driving this divergence.

\section{Data Sources}

I use two main data sources. Data on county per capita personal income is collected from the Bureau of Economic Analysis (BEA) Regional Economic Accounts (US Bureau of Economic Analysis 2017). This is the most common data source used in past evaluations of regional divergence (e.g. Amos 2014; Berry and Glaeser 2005; Ganong and Shoag 2017), and it is available yearly from 1969 to 2015 .

I supplement the BEA data with Census microdata provided by IPUMS for the 1980, 1990, and 2000 Decennial Censuses and the 2006-2010 and 2011-2015 American Community Surveys (Ruggles et al. 2015). Because of top-coding and non-response bias the Census, like other surveys, does an imperfect job of capturing all the income earned in the country (Bollinger et al. 2015). ${ }^{4}$ The Census data is also only available every 10 years until late in the sample 
period. However, because it breaks out income by person it allows for detailed analysis of the entire income distribution, which is necessary for my counterfactual analysis.

\section{Unit of Analysis}

The proper unit of analysis for this study is the metropolitan area, consisting of a core city or cities and the surrounding suburbs. A metro area forms one cohesive unit with its own regional economy. An analysis conducted at the county level would be too fine-grained, since many counties consist primarily of wealthy suburbs whose incomes are generated in nearby cities. An analysis at the state level would be too coarse since it would lump together cities with very little in common, economic or otherwise (New York City and Buffalo share little except for a state government, for example). In my primary analysis I define metro areas using the 1990 Commuting Zones created by the US Department of Agriculture (Tolbert and Sizer 1996). I use Commuting Zones rather than Metropolitan Statistical Areas because they cover rural areas in addition to urban ones. My qualitative results are robust to the use of MSA definitions instead (results available upon request).

\section{Construction of Regional Income Distributions}

I construct metropolitan area income distributions using Census microdata. Publicly available microdata are not identified with the county or metro area of residence but are instead matched to County Groups in the 1980 Census and Public Use Microdata Areas (PUMAs) from the 1990 Census forward. To match these to metro areas I adopt the methodology of Dorn (2009), weighting individual Census records by the proportion of their PUMA's population that falls into a given Commuting Zone or MSA as calculated using the Missouri Census Data 
Center's Geographic Correspondence Engine (Missouri Census Data Center 2012). Unless otherwise stated all calculations Commuting Zones or MSAs are weighted by population in the year observed.

When constructing metropolitan income distributions I focus on economic entities that have remained roughly constant in their propensity to work for income over time to limit the effects of changes in workforce composition. In practice this means using household, family, and adult male incomes. Because labor force participation among women was low in 1980 but rose dramatically in the following decades, and because the extent of that rise varied substantially across metro areas, trends in regional disparities among women are both different from those for families, households, or men and more difficult to interpret. In my primary analysis I use family income, which reports the total before-tax income from all sources of spouses and children living under the same roof. The qualitative results are similar when using household income and adult male income (results available upon request).

\section{Measure of Income Divergence}

There are two types of metric commonly used to measure the convergence and divergence of regional incomes: "sigma divergence" and "beta divergence" (Barro and Sala-iMartin 1990). The more straightforward is sigma divergence, which measures cross-sectional dispersion among regions. A typical measure of sigma divergence is the population-weighted coefficient of variation of per capita income, which divides the standard deviation of per capita income across states or metros by the mean level (Amos 1989; Williamson 1965). Alternative, non-parametric measures include the inter-quartile range or the 10-90 range, both of which measure the difference between high and low percentiles as a percentage of the mean value. 
While sigma divergence looks at the difference across regions at one point in time, beta divergence measures the extent to which poor regions catch up to rich ones over a period of years or decades. This compensates for the possibility of fluidity in the relative position of different regions, where rich regions as a category might be pulling away even as the specific regions who qualify as "rich" change over time. Because beta divergence controls for possible changes in rank, previous research on divergence in economics has used it as the primary measure (Barro and Sala-i-Martin 1992; Baumol 1986; Ganong and Shoag 2017). I show below (Figure 4B) that regional income ranks were reasonably stable during this period, so here I use sigma divergence as my primary measure because of its higher temporal resolution. My qualitative results are robust to the choice of divergence measure, and I present results using beta divergence in Appendix 1.

In the following sections I first replicate previous work showing the marked divergence in regional incomes since the late 1970s. I then show that most of this divergence was driven by changes affecting the richest families and the richest cities. Finally I estimate the contributions of sorting and rising income inequality using counterfactual simulations.

\section{REGIONAL INCOME DIVERGENCE, 1975-2015}

Metropolitan economic fortunes have diverged substantially since the mid-1970s. Figure 2 plots sigma divergence across Commuting Zones over time in per capita personal income as measured by the BEA (panel A) and mean and median family income measured by the Census (panel B) for a variety of parametric and non-parametric measures (coefficient of variation, standard deviation of log income, inter-quartile range, and 90-10 range). All measures show a substantial increase in dispersion since 1980. The coefficient of variation of per capita income 
increased by more than $25 \%$ during this time, while the $10-90$ range increased by half. Family income figures show a similar trend: the coefficient of variation of mean family income across Commuting Zones increased by more than $50 \%$, while that of median family income increased by $34 \%$.

[Figure 2 about here]

\section{The Geography of Income Growth}

As shown in Figure 2, the gap between the richest and poorest parts of the country is now larger than it has been in at least 40 years. But where are these fortunate and left-behind places? Figure 3 maps Commuting Zones by per capita income relative to the nation in 1975 (panel A) and 2015 (panel B). In 1975, the year of maximum convergence, San Francisco and Washington DC were the only major metro areas in the top income category. A huge swath of the country, including both cities and rural areas throughout the Midwest and West, had per capita incomes within $10 \%$ of the national mean, while rural areas in the South and the far north had the lowest incomes.

By 2015 the situation had changed dramatically. Boston, New York, San Jose, and Seattle had joined DC and San Francisco as regions with per capita incomes 20\% greater than average. They were joined by a few resource and tourism-intensive regions in the West and in Florida. The high plains and rural New England managed to keep pace with national income growth, but most other rural areas had fallen behind.

[Figure 3 about here] 
A consequence of this divergence has been the economic polarization of the country. In 1975, roughly $13 \%$ of the US population lived in Commuting Zones with per capita incomes below $80 \%$ of the national average. By 2015 that share had increased to $17 \%$, a $30 \%$ increase. On the other extreme, just 9\% of the population in 1975 lived in the extremely wealthy cities with per capita incomes 20\% larger than the nation as a whole. By $201516 \%$ did, a rise of $80 \%$. In total, the fraction of Americans living in especially rich or especially poor metros rose by half, from $22 \%$ to $31 \%$. This divergence is similar in kind if smaller in degree than the concurrent polarization of residents into rich and poor neighborhoods within metro areas (Reardon and Bischoff 2016).

\section{REGIONAL DIVERGENCE AND THE TOP OF THE INCOME DISTRIBUTION}

Regional divergence could be caused by rich parts of the country pulling ahead over the last 40 years, leaving the rest of the country behind. Alternatively, poor places could have gotten poorer relative to the rest of the nation than they already were. Or the entire distribution could be stretching out without a disproportionate effect in any one part. At the individual level, divergence could result from changes in the geographic distribution and earnings of the wealthy, those of the poor, or some combination.

\section{Rich Regions Drive Divergence}

Figure 4 shows that rich cities are the primary drivers of divergence. Panel A plots the $10^{\text {th }}, 50^{\text {th }}$, and $90^{\text {th }}$ percentiles of regional per capita income over time. The dominant trend has been the pulling away of the top. In the late 1970s the Commuting Zone at the $90^{\text {th }}$ percentile had 
a per capita income about $16 \%$ higher than the national median. By 2015 the gap between the $90^{\text {th }}$ percentile and the median had increased to $38 \%$. Meanwhile income at the $10^{\text {th }}$ percentile has remained constant at about $75 \%$ of the median. Over the last 40 years, the difference between the middle and the bottom of the distribution has remained fairly constant, while the most fortunate places have pulled away.

[Figure 4 about here]

Panel B of Figure 4 plots per capita income as a percentage of the national mean for each Commuting Zone in 1975 and 2015. The Commuting Zones above the dotted line got richer relative to the nation during this period while those below the dotted line got poorer. Across most of the income distribution the dots are clustered near the line, with similar numbers above and below. This strong positive relationship between per capita income in 1975 and 2015 suggests that regions have been fairly stable in income rank on the whole, although individual Commuting Zones have moved up (e.g. Boston) or down (Los Angeles or Miami). The linear relationship breaks down for the richest Commuting Zones, though: probably the most striking feature of the graph is the cluster of large cities well above the dotted line in the top-right portion of the graph. These places — specifically Boston, New York, and San Francisco-were already richer than average in 1975, but since then they have surged further ahead.

\section{Rich People Drive Divergence}

To estimate the extent to which regional divergence is being driven by individuals at the top of the income distribution I re-compute divergence measures in the Census data after 
removing the highest income families in the country. Trends in the coefficient of variation of mean family income are shown in Figure 5. Top earners drive a huge portion of the overall variation in regional mean incomes: the increase in dispersion among the bottom $90 \%$ of families is just a quarter as large as the increase across the entire distribution. Even just removing the top $1 \%$ shrinks the amount of divergence since 1980 by about half. Similar patterns occur in the non-parametric statistics and when using median rather than mean income (available on request).

[Figure 5 about here]

\section{REGIONAL INCOME DIVERGENCE AS A FUNCTION OF MACRO-LEVEL INCOME}

\section{INEQUALITY}

To determine the relative importance of income sorting and income inequality in driving divergence I conduct a series of simulations where I independently vary each factor on its own. I operationalize income sorting by calculating the percentage of each Commuting Zone's families in each quantile of the national income distribution for each Census year from 1980-2015. ${ }^{6}$ Income inequality is measured by computing the ratio of mean income within each national quantile to the overall national mean.

To isolate the impact of each factor I allow either the percentage of each Commuting Zone's families in each national income quantile or the shape of the national income distribution to evolve as it did from 1980-2015 while holding the other factor constant at 1980 levels. I then re-compute the mean income for each metro area under the hypothetical scenario. With this information I can calculate measures of sigma and beta divergence under counterfactual 
scenarios where only the geographic distribution of earners or only the earnings associated with each income percentile changed. Comparing these measures to the observed trends allows me to determine the independent effects of sorting and inequality.

Figure 6 plots the coefficient of variation of Commuting Zone mean family income over time under the various hypothetical scenarios. The dotted line verifies that if both the geographic distribution and the income levels relative to national mean income had remained constant at 1980 levels there would have been no further regional income dispersion. The solid line shows the regional divergence in family incomes that actually happened. From 1980-2015 the coefficient of variation of mean family income across Commuting Zones grew from $12.9 \%$ to $20.1 \%$, an increase of $56 \%$.

[Figure 6 about here]

The dashed lines show the dispersion that would have happened under the two counterfactual scenarios. Much of the divergence in the 1980s appears to have been due to geographical sorting: keeping the 1980 income distribution but sorting people across geography as they were in 1990 results in more than half as much dispersion from 1980 to 1990 as occurred in reality. But after 1990 the importance of geographical sorting declined substantially and the role of income inequality increased. In all, about $53 \%$ of the increase in the coefficient of variation of Commuting Zone mean family income from 1980-2015 was due solely to increasing national inequality, about $23 \%$ was due solely to increased geographical concentration, and the remaining $24 \%$ was due to interactions between the two (specifically, the effect of rising 
incomes for rich families was magnified by their increased geographic concentration, as in Panel D of Figure 1).

The qualitative finding from Figure 6-that the rise in macro-level income inequality would have resulted in substantial regional divergence without any increased geographic concentration, and that the reverse is less true - is robust to a variety of income measurements (household income, family income, and individual income for adult men and men aged 25-54) and measures of sigma divergence (coefficient of variation, inter-quartile range, and 10-90 range). The baseline results weight cities by their observed population in each year. Because divergence could be affected by changes in Commuting Zone populations between 1980 and 2015 I also run specifications that weight cities in all years by their 1980 population and by their 2015 population. This does not meaningfully affect the results (if 1980 population weights are used, $26 \%$ and $52 \%$ of the increase in the coefficient of variation for mean family income are attributable to sorting and inequality respectively; if 2015 population is used the proportions are $25 \%$ and $54 \%)$.

The maps in Figure 7 visualize the independent geographic effects of income inequality and income sorting. Panel A shows the observed mean family income of each Commuting Zone in 1980. Panel D shows the observed means in 2015. The divergence is apparent: while the map in panel A is largely grey, indicating that most places had incomes between $80 \%$ and $120 \%$ of the national average, panel D is dominated by the black of Commuting Zones $20 \%$ richer than the nation as a whole and the white of those more than $20 \%$ poorer. Panels B and C show the regional income distributions under the counterfactuals where inequality is held constant (B) and sorting is held constant (C). The map in panel B is much more similar to panel A than to panel D, with lots of grey and few dark colors. Sorting alone would have been enough to put several 
coastal metros into the top income bracket, but would have left much of the country with incomes roughly in line with the national average. In contrast, the map in panel $\mathrm{C}$ shows more similarity to panel D, with a larger number of extremely high- and low-income metro areas.

[Figure 7 about here]

\section{Alternative Measures of Income Sorting}

Despite the increasing divergence of regional incomes, most inequality in the United States remains within rather than across Commuting Zones. To show this, I calculate the proportion of total national variation in family incomes that is between cities. In 1980 only about $3.3 \%$ of total income variation was across Commuting Zones. As shown by the solid line in

Figure 8 , this proportion has remained fairly constant, rising just $7 \%$ by 2015 , to a value of $3.6 \%$. During this time the coefficient of variation of mean family income across Commuting Zones rose by more than half. That this proportion has remained steady further suggests that income sorting has played a relatively modest role in driving regional divergence.

[Figure 8 about here]

A second way to estimate the contribution of sorting to divergence is to compute a rankbased measure of income segregation across Commuting Zones, such as Reardon and Bischoff's rank order information theory measure $H$ (Reardon and Bischoff 2011). They find that income segregation between Census Tracts within metro areas increased by about 30\% between 1980 and 2012 (Reardon and Bischoff 2016, Table 2). The dotted line in Figure 8 plots the rank-order 
information theory measure of income segregation across Commuting Zones as measured by $H$ over time. Interestingly, income segregation across Commuting Zones increased by only about $6 \%$ during this period, a much smaller increase than that observed within metro areas by Reardon and Bischoff. This suggests that the processes driving migration between metropolitan regions may be different from those driving relocation within regions, and again reinforces the conclusion that the role of income sorting in divergence may be relatively minor.

A third way to estimate the amount of income sorting is to calculate Zhou's $S$, a measure of the extent to which categorical groups such as races, genders, or occupations are stratified along a continuous spectrum, such as income (Zhou 2012). Because it is too computationally intensive to compute $S$ on the full sample, I compute this measure for a subsample of 100,000 observations in each year, producing an estimate of how stratified Commuting Zones are by income. As shown by the dashed line in Figure 8, $S$ behaves similarly to the previous two measures, increasing by about $11 \%$ over the sample period - again much less than the amount regions have diverged.

\section{DISCUSSION AND LIMITATIONS}

In this paper I have made two major contributions to knowledge of regional income disparities. First, I have shown that the observed divergence over the last 40 years has been almost entirely due to changes at the top of the metropolitan and individual income distributions. Regional variation in incomes has not changed much outside the richest $10 \%$ of families. Second, I have estimated how much divergence can be attributed to sorting and how much to rising national income inequality. If inequality had not increased, the observed sorting would have produced only about a quarter as much divergence as actually occurred. But if there had 
been no income sorting whatsoever, the observed rise in inequality would have produced just over half as much divergence as actually occurred. The primary driver of regional divergence over the past 40 years is thus not changes in who lives where but a national trend of increased inequality that has interacted with preexisting regional income distributions in geographically textured ways. Regional income divergence conforms with phenomena from mass incarceration to industrial automation in that preexisting spatial inequality has caused a single macro-level shift to have very uneven spatial effects.

These findings carry important implications for studies of regional economic outcomes. First, while most previous accounts of divergence have focused on workers' education and skill levels (e.g. Giannone 2017; Moretti 2012), the outsize importance of very high income families suggests that divergence is more likely a function of workers' incomes. Most of the observed divergence across regions is driven by changes among the highest-earning $10 \%$ of the population. While many of these people are college-educated, they can comprise only a minority of all college graduates, who collectively make up almost a third of US adults (US Census Bureau 2015).

Second, these results suggest that the sorting-based explanations for regional divergence prominent in the literature may be missing a major part of the story. Figuring out what attracts high-income workers to one city over another or whether housing costs are preventing lowincome people from moving to affluent areas may be important for understanding the rise and fall of individual cities, but those processes do not fully explain why rich places as a whole are now so much wealthier than the rest of the country. That development appears to be more a function of changes in the amount of money high-income people make than changes in where they live. 
It is important to note the limitations of this analysis. Most importantly, I am not directly commenting on the economic fortunes of any particular place. Individual cities have moved up and down the income ladder a great deal since 1980. Boston, for instance, grew from being about $9 \%$ to almost $40 \%$ richer than average during my period of study, while Los Angeles fell from being almost $20 \%$ to barely $3 \%$ better off than the mean. Other scholars have investigated what specific factors promote regional growth in both large-n analyses (e.g. Kemeny and Storper 2012; Partridge 2010) and case studies (e.g. Saxenian 1996; Storper et al. 2015). Successfully attracting and retaining skilled workers almost certainly plays a role in securing the prosperity of any one city. My results speak instead to the overall level of dispersion across metro areas-why it is that the richest cities in 1980 were about $35 \%$ richer than the county as a whole, while they are almost $60 \%$ richer today. I have shown that this yawning gap is primarily because the richest people have gotten richer, and only secondarily because they have further concentrated themselves into a few fortunate places.

My results also do not necessarily imply that agglomeration economies, barriers to migration, or other drivers of income sorting are unimportant. But beyond the $23 \%$ of observed divergence that is directly attributable to sorting, their impact is likely felt more because they perpetuate inequality and less because they concentrate workers by income. If today's high wage jobs are disproportionately found in highly agglomerative industries, that still may contribute to regional divergence. But it is the high wages these industries pay and not their geographic profile that is driving the trend.

CONCLUSION 
With any spatially patterned social outcome, a core question for social scientists is the scale of the driving process. Does a changing map reflect the myriad idiosyncratic decisions of individual people and organizations? Or is it a consequence of one national trend interacting with existing spatial structures? In this paper I have demonstrated that the regional income divergence the US has experienced over the last four decades largely falls into the latter category. By applying insights on the interaction between spatial structure and macro-level trends developed in the study of neighborhood poverty, I have shown that the past 40 years of regional income divergence are primarily a case of national-level income dispersion exacerbating previously existing spatial inequalities. The major change in the economic geography of the US during this time was not in who lives where but in how much money they make.

A corollary to this finding is that the various potential downsides to regional divergence - macroeconomic policy challenges, political dysfunction, reduced social mobility, etc. - are perhaps best understood as yet more malign consequences of the concentration of economic resources. The doubling of the income share going to the richest $1 \%$ is mathematically inseparable from the income stagnation that has occurred in regions where they don't happen to live. Hollowed-out towns in middle America are inextricably tied to the same institutional structures, technological changes, and rent-seeking behaviors that have enriched a small slice of the population primarily residing in a handful of major cities.

Although my investigation has focused on space, the mechanism driving it is not inherently spatial. It generalizes to any social structure with strong with strong correlations between graduated and nominal parameters (Blau 1974, 1977). Once nominal groups-races, genders, occupations, Commuting Zones — are sorted by income or by any other graduated parameter, changes along that parameter are sufficient to affect inter-group inequality. No further 
group-based stratification is necessary. This dynamic appears to be important in explaining the persistence of race and gender wage gaps in the United States over the past five decades (Bayer and Charles 2016; Blau and Kahn 1996; Juhn, Murphy, and Pierce 1991; Mandel and Semyonov 2005; Author 2018). In this paper I have demonstrated that it applies to inequalities between regions of the country as well. Like inequalities between races or genders, disparities between regions are in large part determined by the level of inequality in the country as a whole.

On some level, the message of this study is a core claim of human geography: every social process is spatially situated. Because people are distributed unevenly across places, any process that affects some types of people more than others will have varied effects on places as well. As social scientists of all stripes increasingly recognize the importance of context and place in the phenomena they study (e.g. Logan, 2012; Voss, 2007), internalizing this truth will be critical. 


\section{ENDNOTES}

1. Restrictions on migration, one mechanism behind income sorting, may also contribute to income inequality in that they can reduce movement from low- to high-wage labor markets, which would otherwise push wages up in poor areas and down in rich ones. This mechanism is not typically considered to be a primary driver of inequality at the national level, however. The opposite effect is likely true as well: a rise in inequality will induce some income sorting as wealthy residents use their increasing incomes to bid up the price of housing in attractive areas (Gyourko et al., 2013).

2. Most previous research has studied sorting based on human capital, typically operationalized as the spatial concentration of college graduates. In this paper I focus on income sorting, the extent to which people at a given percentile of the national income distribution are found in the same cities and towns as one another. Income is more precisely defined than human capital, and personal incomes are constitutive of regional income distributions while education levels or other human capital measures are merely correlated with them. This makes a decomposition based on income conceptually and empirically cleaner than one based on education.

3. Note that income sorting can occur among people or jobs. Because of the way the Census data are constructed, it is impossible to tell whether for instance an increase in the number of people in a given city who rank in the top $1 \%$ of the income distribution occurs because new high-income workers move to that city or because a new high-paying job is created in that city, perhaps giving a raise to a worker who already lived there. I consider these both instances of income sorting because they result in the geographic concentration of high incomes. 
4. The total proportion of GDP accounted for in the Census during my sample period ranges from $77.8 \%$ in 1980 to $65.3 \%$ in 2015 .

5. This minimal overall trend masks substantial heterogeneity by city size. Small metro areas (populations under 300,000) show a strong trend of convergence, while large ones show substantial divergence. A similar heterogeneity in convergence patterns was noted by Giannone (2017), who showed that college-educated workers have seen regional divergence in wages since 1980 while non-college workers have seen continued convergence.

6. In the primary analysis I use 50 quantile buckets of two percentiles each, but the results are robust to sizes ranging from 1 to 10 percentiles. I also include as a component of income sorting the ratio of mean income for a given quantile in each Commuting Zone to mean income in that quantile for the nation. 


\section{REFERENCES}

Amos, Orley M. 1989. “An Inquiry into the Causes of Increasing Regional Income Inequality in The United States.” The Review of Regional Studies 19 (2): 1-12.

Amos, Orley M. 2014. "Evidence of Increasing Regional Income Variation in the United States: 1969-2006." Modern Economy 5: 520-32.

Autor, David H, and David Dorn. 2013. "The Growth of Low-Skill Service Jobs and the Polarization of the US Labor Market.” American Economic Review 103 (5): 1553-97.

Autor, David H, David Dorn, and Gordon H Hanson. 2013. “The Geography of Trade and Technology Shocks in the United States.” American Economic Review 103 (3): 220-25.

Autor, David H., David Dorn, and Gordon H. Hanson. 2016. “The China Shock: Learning from Labor Market Adjustment to Large Changes in Trade.” National Bureau of Economic Research.

Autor, David H., Lawrence F. Katz, and Alan B. Krueger. 1998. “Computing Inequality: Have Computers Changed the Labor Market?" The Quarterly Journal of Economics 113 (4): $1169-1213$.

Autor, David H., Frank Levy, and Richard J. Murnane. 2003. “The Skill Content of Recent Technological Change: An Empirical Exploration.” Quarterly Journal of Economics 118 (4): 1279-1333.

Avent, Ryan. 2011. The Gated City. Seattle: Amazon Digital Services.

Barro, Robert J., and Xavier Sala-i-Martin. 1990. "Economic Growth and Convergence across the United States.” National Bureau of Economic Research.

Barro, Robert J., and Xavier Sala-i-Martin. 1991. "Convergence across States and Regions.” Brookings Papers on Economic Activity, 107-82. 
Barro, Robert J., and Xavier Sala-i-Martin. 1992. “Convergence.” Journal of Political Economy 100 (2): $223-51$.

Baumol, William J. 1986. "Productivity Growth, Convergence, and Welfare: What the Long-Run Data Show." The American Economic Review 76 (5): 1072-85.

Bayer, Patrick, and Kerwin Kofi Charles. 2016. "Divergent Paths: Structural Change, Economic Rank, and the Evolution of Black-White Earnings Differences, 1940-2014.” National Bureau of Economic Research.

Beramendi, Pablo. 2007. "Inequality and the Territorial Fragmentation of Solidarity." International Organization 61 (4): 783-820.

Beramendi, Pablo. 2012. The Political Geography of Inequality: Regions and Redistribution. Cambridge, UK: Cambridge University Press.

Berry, Christopher R., and Edward L. Glaeser. 2005. "The Divergence of Human Capital Levels across Cities." Papers in Regional Science 84 (3): 407-44.

Binder, Amy J., Daniel B. Davis, and Nick Bloom. 2015. "Career Funneling How Elite Students Learn to Define and Desire “Prestigious” Jobs.” Sociology of Education 89 (1): $20-39$.

Bischoff, Kendra, and Sean F. Reardon. 2014. "Residential Segregation by Income, 1970-2009." Pp. 208-233 in Diversity and Disparities: America Enters a New Century, edited by John R. Logan. New York: Russell Sage Foundation.

Blau, Francine D., and Lawrence M. Kahn. 1996. "Wage Structure and Gender Earnings Differentials: An International Comparison.” Economica 63 (250): S29-S62.

Blau, Peter M. 1974. "Presidential Address: Parameters of Social Structure." American Sociological Review 39 (5): 615-35. 
Blau, Peter M. 1977. "A Macrosociological Theory of Social Structure.” American Journal of Sociology, 26-54.

Bollinger, Christopher R., Barry T. Hirsch, Charles M. Hokayem, and James P. Ziliak. 2015. "Trouble in the Tails: Earnings Non-Response and Response Bias across the Distribution." Working paper.

Bruch, Elizabeth E. 2014. "How Population Structure Shapes Neighborhood Segregation.” American Journal of Sociology 119 (5): 1221-78.

Bruch, Elizabeth E., and Robert D. Mare. 2006. "Neighborhood Choice and Neighborhood Change.” American Journal of Sociology 112 (3): 667-709.

Carr, Patrick J., and Maria J. Kefalas. 2009. Hollowing out the Middle: The Rural Brain Drain and What It Means for America. Boston: Beacon Press.

Chetty, Raj, and Nathaniel Hendren. 2016. "The Impacts of Neighborhoods on Intergenerational Mobility I: Childhood Exposure Effects." National Bureau of Economic Research. Chetty, Raj, Nathaniel Hendren, Patrick Kline, and Emmanuel Saez. 2014. "Where Is the Land of Opportunity? The Geography of Intergenerational Mobility in the United States.” The Quarterly Journal of Economics 129 (4): 1553-1623.

Clark, Terry Nichols, Richard Lloyd, Kenneth K. Wong, and Pushpam Jain. 2002. “Amenities Drive Urban Growth.” Journal of Urban Affairs 24 (5): 493-515.

Clark, William AV. 1991. "Residential Preferences and Neighborhood Racial Segregation: A Test of the Schelling Segregation Model.” Demography 28 (1): 1-19.

Comanor, William S., and Robert H. Smiley. 1975. "Monopoly and the Distribution of Wealth." The Quarterly Journal of Economics 89 (2): 177-94. 
Dahl, Michael S., and Olav Sorenson. 2010. "The Social Attachment to Place.” Social Forces 89 (2): $633-58$.

Diamond, Rebecca. 2016. “The Determinants and Welfare Implications of U.S. Workers' Diverging Location Choices by Skill: 1980-2000.” American Economic Review 106 (3): $479-524$.

Dorn, David. 2009. "Essays on Inequality, Spatial Interaction, and the Demand for Skills." $\mathrm{PhD}$ dissertation, Department of Economics, University of St. Gallen, St. Gallen, Switzerland.

Fan, C. Cindy, and Emilio Casetti. 1994. "The Spatial and Temporal Dynamics of US Regional Income Inequality, 1950-1989.” The Annals of Regional Science 28 (2): 177-96.

Florida, Richard. 2002. The Rise of the Creative Class. New York: Basic Books.

Ganong, Peter, and Daniel Shoag. 2017. "Why Has Regional Income Convergence in the US Declined?" National Bureau of Economic Research.

Giannone, Elisa. 2017. "Skilled-Biased Technical Change and Regional Convergence.” Working paper.

Glaeser, Edward L., and Joshua D. Gottlieb. 2009. "The Wealth of Cities: Agglomeration Economies and Spatial Equilibrium in the United States." Journal of Economic Literature 47 (4): 983-1028.

Glaeser, Edward L., Jed Kolko, and Albert Saiz. 2001. "Consumer City.” Journal of Economic Geography 1 (1): 27-50.

Gotham, Kevin Fox. 2000. “Urban Space, Restrictive Covenants and the Origins of Racial Residential Segregation in a US City, 1900-50." International Journal of Urban and Regional Research 24 (3): 616-33. 
Gyourko, Joseph, Christopher J. Mayer, and Todd M. Sinai. 2013. "Superstar Cities.” American Economic Journal: Economic Policy 5 (4): 167-99.

Hacker, Jacob S., and Paul Pierson. 2010. Winner-Take-All Politics. New York: Simon \& Schuster.

Hsieh, Chang-Tai, and Enrico Moretti. 2017. "Housing Constraints and Spatial Misallocation." Working paper.

Hwang, Jackelyn, Michael Hankinson, and Kreg Steven Brown. 2015. "Racial and Spatial Targeting: Segregation and Subprime Lending within and across Metropolitan Areas.” Social Forces 93 (3): 1081-1108.

Hyra, Derek S., Gregory D. Squires, Robert N. Renner, and David S. Kirk. 2013. "Metropolitan Segregation and the Subprime Lending Crisis.” Housing Policy Debate 23 (1): 177-198.

Juhn, Chinhui, Kevin M. Murphy, and Brooks Pierce. 1991. “Accounting for the Slowdown in Black-White Wage Convergence.” Pp. 107-43 in Workers and Their Wages, edited by Marvin H. Kosters. Washington DC: AEI Press.

Kemeny, Thomas, and Michael Storper. 2012. "The Sources of Urban Development: Wages, Housing, and Amenity Gaps Across American Cities.” Journal of Regional Science 52 (1): $85-108$.

Kurgan, Laura, Eric Cadora, David Reinfurt, Sarah Williams, and Leah Meisterlin. 2012. “Million Dollar Blocks.” New York: Spatial Information Design Laboratory at Columbia University. Retrieved May 16, 2017 (http://spatialinformationdesignlab.org/projects.php\%3Fid\%3D16)

Lee, David S. 1999. "Wage Inequality in the United States during the 1980s: Rising Dispersion or Falling Minimum Wage?" Quarterly Journal of Economics, 977-1023. 
Lemieux, Thomas. 2006. "Increasing Residual Wage Inequality: Composition Effects, Noisy Data, or Rising Demand for Skill?” The American Economic Review 96 (3): 461-98.

Lobao, Linda M., and Gregory Hooks. 2007. “Advancing the Sociology of Spatial Inequality: Spaces, Lpaces, and the Subnational Scale.” Pp. 29-61 in The Sociology of Spatial Inequality, edited by Linda M. Lobao, Gregory Hooks, and Ann R. Tickamyer. Albany: SUNY Press.

Logan, John R. 1978. "Growth, Politics, and the Stratification of Places.” American Journal of Sociology, 404-16.

Logan, John R. 2012. "Making a Place for Space: Spatial Thinking in Social Science.” Annual Review of Sociology 38 (1): 507-524.

Longman, Phillip. 2015. “Bloom and Bust.” Washington Monthly, November-December issue. Mandel, Hadas, and Moshe Semyonov. 2005. "Family Policies, Wage Structures, and Gender Gaps: Sources of Earnings Inequality in 20 Countries.” American Sociological Review 70 (6): 949-67.

Massey, Douglas S. 1990. “American Apartheid: Segregation and the Making of the Underclass." American Journal of Sociology 96 (2): 329-57.

Massey, Douglas S., Andrew B. Gross, and Kumiko Shibuya. 1994. "Migration, Segregation, and the Geographic Concentration of Poverty." American Sociological Review 59 (3): 425-45.

McCall, Leslie. 2000. “Explaining Levels of within-Group Wage Inequality in US Labor Markets.” Demography 37 (4): 415-30.

Meyer, Stephen Grant. 2001. As Long as They Don't Move next Door: Segregation and Racial Conflict in American Neighborhoods. Lanham, MD: Rowman \& Littlefield. 
Missouri Census Data Center. 2012. MABLE/Geocorr12, Version 1.2: Geographic

Correspondence Engine. http://mcdc.missouri.edu/websas/geocorr12.html.

Moller, Stephanie, Alderson, Arthur S., and Nielsen, Francois. 2009. "Changing Patterns of Income Inequality in US Counties, 1970-2001.” American Journal of Sociology 114 (4): $1037-1101$.

Moretti, Enrico. 2012. The New Geography of Jobs. Boston: Houghton Mifflin Harcourt.

Owens, Ann. 2016. “Inequality in Children's Contexts: Income Segregation of Households with and without Children." American Sociological Review 81 (3): 549-74.

Partridge, Mark D. 2010. “The Duelling Models: NEG vs Amenity Migration in Explaining US Engines of Growth.” Papers in Regional Science 89 (3): 513-36.

Piketty, Thomas, Emmanuel Saez, and Stefanie Stantcheva. 2014. "Optimal Taxation of Top Labor Incomes: A Tale of Three Elasticities.” American Economic Journal: Economic Policy 6 (1): 230-71.

Piketty, Thomas, Emmanuel Saez, and Gabriel Zucman. 2016. "Distributional National Accounts: Methods and Estimates for the United States.” National Bureau of Economic Research.

Quillian, Lincoln. 1999. "Migration Patterns and the Growth of High-Poverty Neighborhoods, 1970-90." American Journal of Sociology 105 (1): 1-37.

Quillian, Lincoln. 2012. "Segregation and Poverty Concentration the Role of Three Segregations." American Sociological Review 77 (3): 354-79.

Reardon, Sean F., and Kendra Bischoff. 2011. "Income Inequality and Income Segregation." American Journal of Sociology 116 (4): 1092-1153. 
Reardon, Sean F., and Kendra Bischoff. 2016. "The Continuing Increase in Income Segregation, 2007-2012." Palo Alto, CA: Stanford Center for Education Policy Analysis.

Rothwell, Jonathan, and Douglas S. Massey. 2009. "The Effect of Density Zoning on Racial Segregation in US Urban Areas." Urban Affairs Review 44 (6): 779-806.

Ruggles, Steven, Katie Genadek, Ronald Goeken, Josiah Grover, and Matthew Sobek. 2015. Integrated Public Use Microdata Series: Version 6.0. Minneapolis: University of Minnesota. http://doi.org/10.18128/D010.V6.0.

Sampson, Robert J. 2012. Great American City: Chicago and the Enduring Neighborhood Effect. Chicago: University of Chicago Press.

Sampson, Robert J., and Charles Loeffler. 2010. “Punishment's Place: The Local Concentration of Mass Incarceration.” Daedalus 139 (3): 20-31.

Sampson, Robert J., Jared N. Schachner, and Robert D. Mare. 2017. "Urban Income Inequality and the Great Recession in Sunbelt Form: Disentangling Individual and NeighborhoodLevel Change in Los Angeles." RSF.

Sampson, Robert J., and Patrick Sharkey. 2008. "Neighborhood Selection and the Social Reproduction of Concentrated Racial Inequality." Demography 45 (1): 1-29.

Saxenian, AnnaLee. 1996. Regional Advantage. Cambridge, MA: Harvard University Press.

Schelling, Thomas C. 1971. "Dynamic Models of Segregation.” Journal of Mathematical Sociology 1 (2): 143-86.

Schleicher, David. 2017. "Stuck in Place: Law and the Economic Consequences of Residential Stability." Social Science Research Network. 
Sharkey, Patrick, and Jacob W. Faber. 2014. "Where, When, Why, and For Whom Do Residential Contexts Matter? Moving Away from the Dichotomous Understanding of Neighborhood Effects.” Annual Review of Sociology 40 (1): 559-79.

Stiglitz, Joseph E. 2015. Rewriting the Rules of the American Economy: An Agenda for Growth and Shared Prosperity. New York: W.W. Norton \& Company.

Storper, Michael, Thomas Kemeny, Naji Makarem, and Taner Osman. 2015. The Rise and Fall of Urban Economies: Lessons from San Francisco and Los Angeles. Palo Alto, CA: Stanford University Press.

Storper, Michael, and Allen J. Scott. 2009. "Rethinking Human Capital, Creativity and Urban Growth.” Journal of Economic Geography 9 (2): 147-67.

Tiebout, Charles M. 1956. “A Pure Theory of Local Expenditures.” Journal of Political Economy 64 (5): 416-424.

Tolbert, Charles M., and Molly Sizer. US Commuting Zones and Labor Market Areas: A 1990 Update. Washington, DC: USDA Economic Research Service, 1996. https://www.ers.usda.gov/data-products/commuting-zones-and-labor-market-areas/

Urzúa, Carlos M. 2013. “Distributive and Regional Effects of Monopoly Power.” Economía Mexicana Nueva Época 22 (2): 279-295.

US Bureau of Economic Analysis. Regional Economic Accounts [computer file]. Washington, DC, 2017. https://www.bea.gov/regional/.

US Census Bureau. 2015. "Sex by Age by Educational Attainment for the Population 18 Years and Over.” B15001. 2011-2015 American Community Survey 5-Year Estimates. Washington DC. 
Voss, Paul R. 2007. "Demography as a spatial social science.” Population Research and Policy Review 26 (5-6): 457-476.

Weeden, Kim A. 2002. "Why Do Some Occupations Pay More than Others? Social Closure and Earnings Inequality in the United States 1.” American Journal of Sociology 108 (1): 55101.

Weeden, Kim A., and David B. Grusky. 2014. "Inequality and Market Failure." American Behavioral Scientist 58 (3): 473-491.

Western, Bruce, and Jake Rosenfeld. 2011. "Unions, Norms, and the Rise in US Wage Inequality." American Sociological Review 76 (4): 513-537.

Williamson, Jeffrey G. 1965. "Regional Inequality and the Process of National Development: A Description of the Patterns." Economic Development and Cultural Change 13 (4): 1-84.

Wilson, Valerie, and William M. III Rodgers. 2016. "Black-White Wage Gaps Expand with Rising Wage Inequality.” Washington DC: Economic Policy Institute.

Wilson, William Julius. 1987. The Truly Disadvantaged: The Inner City, the Underclass, and Public Policy. Chicago: University of Chicago Press.

Yglesias, Matthew. 2012. The Rent Is Too Damn High: What To Do About It, And Why It Matters More Than You Think. New York: Simon \& Schuster.

Zhou, Xiang. 2012. “A Nonparametric Index of Stratification.” Sociological Methodology 42(1): $365-389$. 


\section{FIGURES}
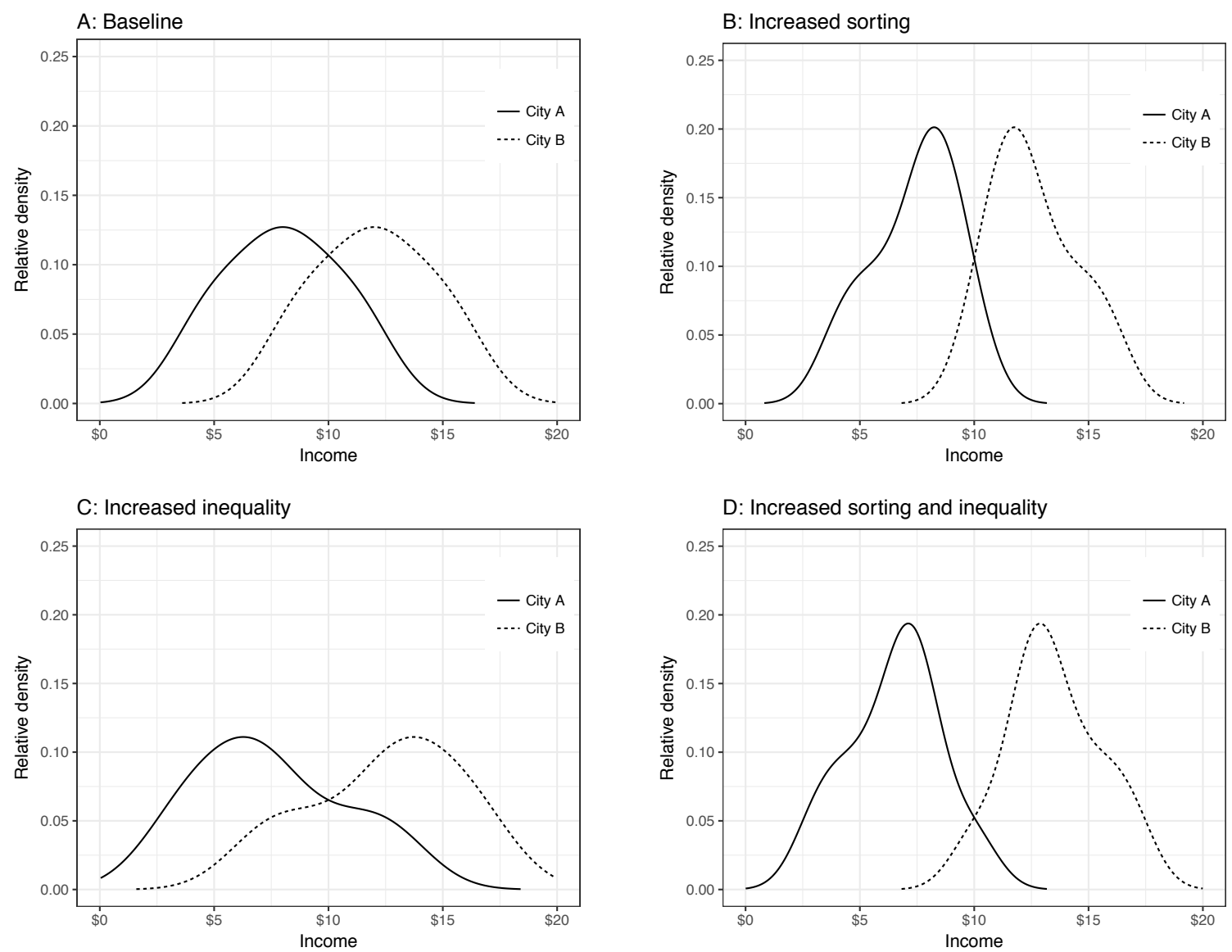

Figure 1: Hypothetical regional divergence scenarios 

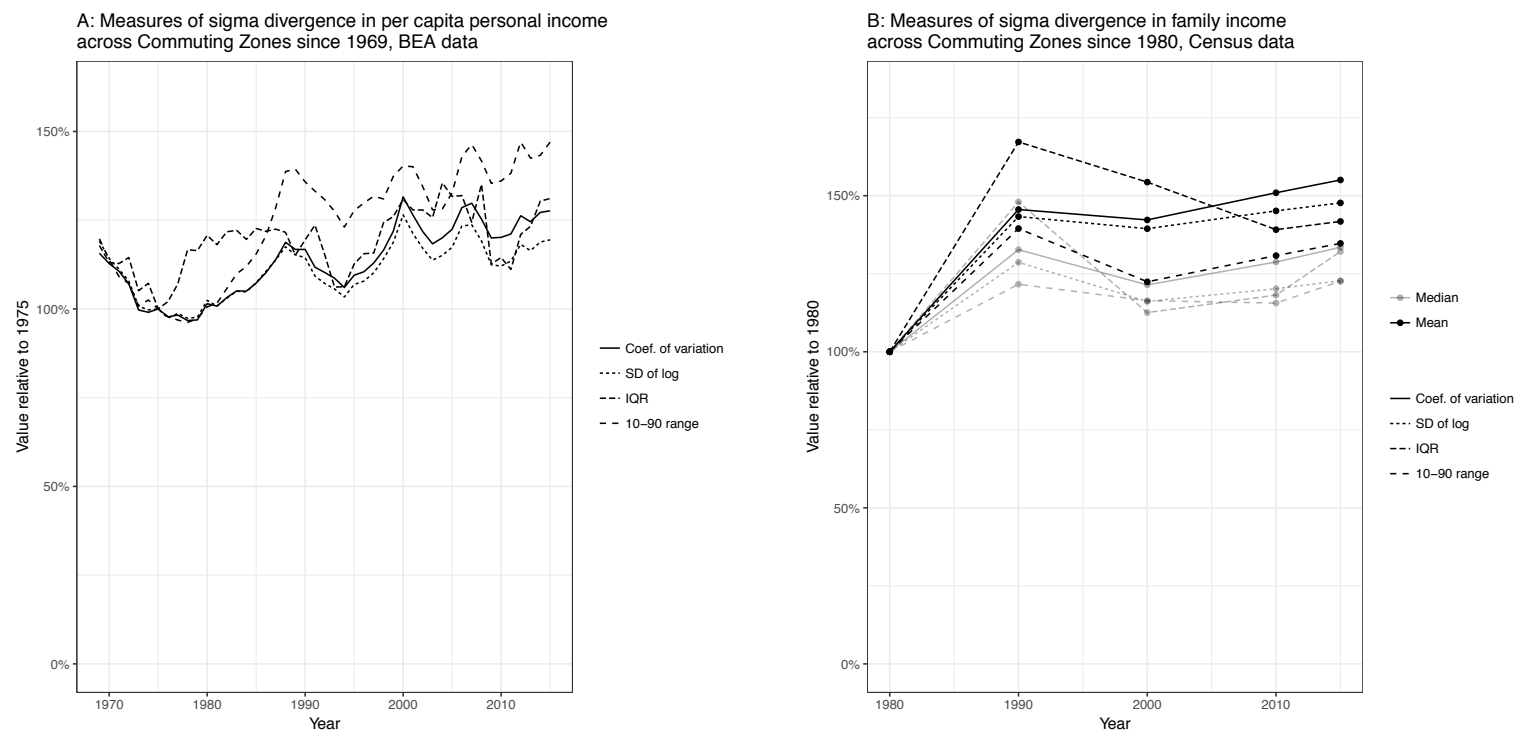

Figure 2: Sigma divergence across Commuting Zones over time in per capita personal income (A) and mean and median family income (B) 
A:Commuting Zone per capita personal income

relative to nation, 1975

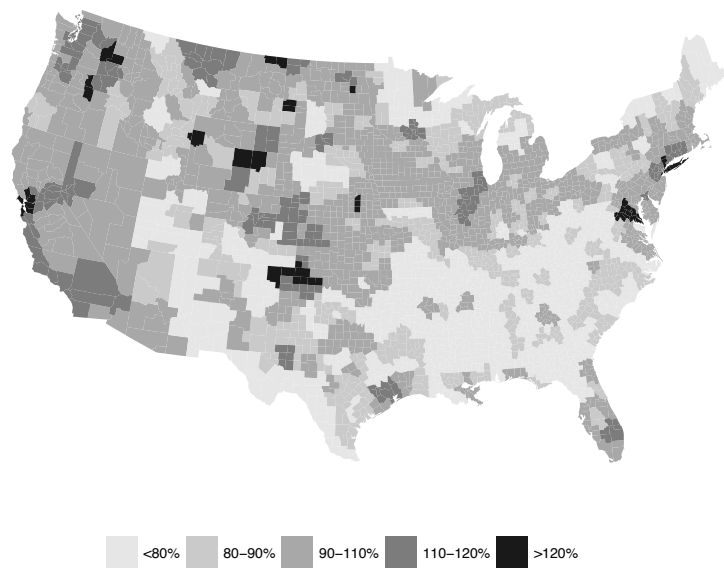

B:Commuting Zone per capita personal income relative to nation, 2015

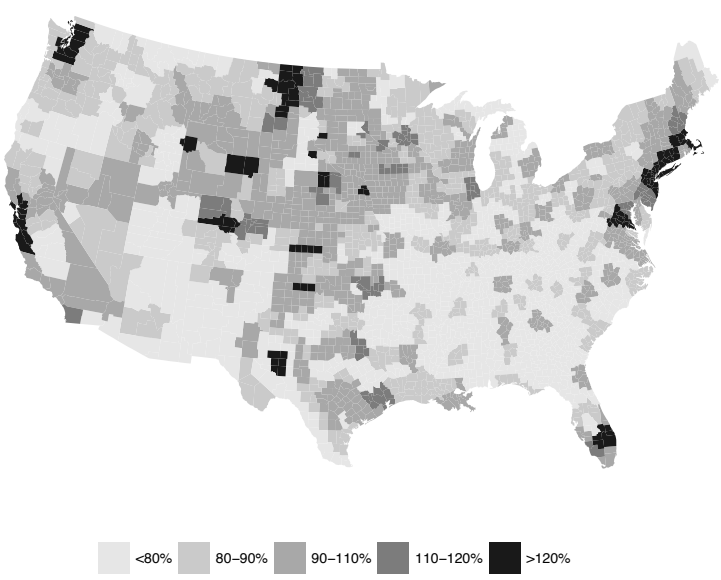

Figure 3: Commuting Zone per capita income, 1975 and 2015 

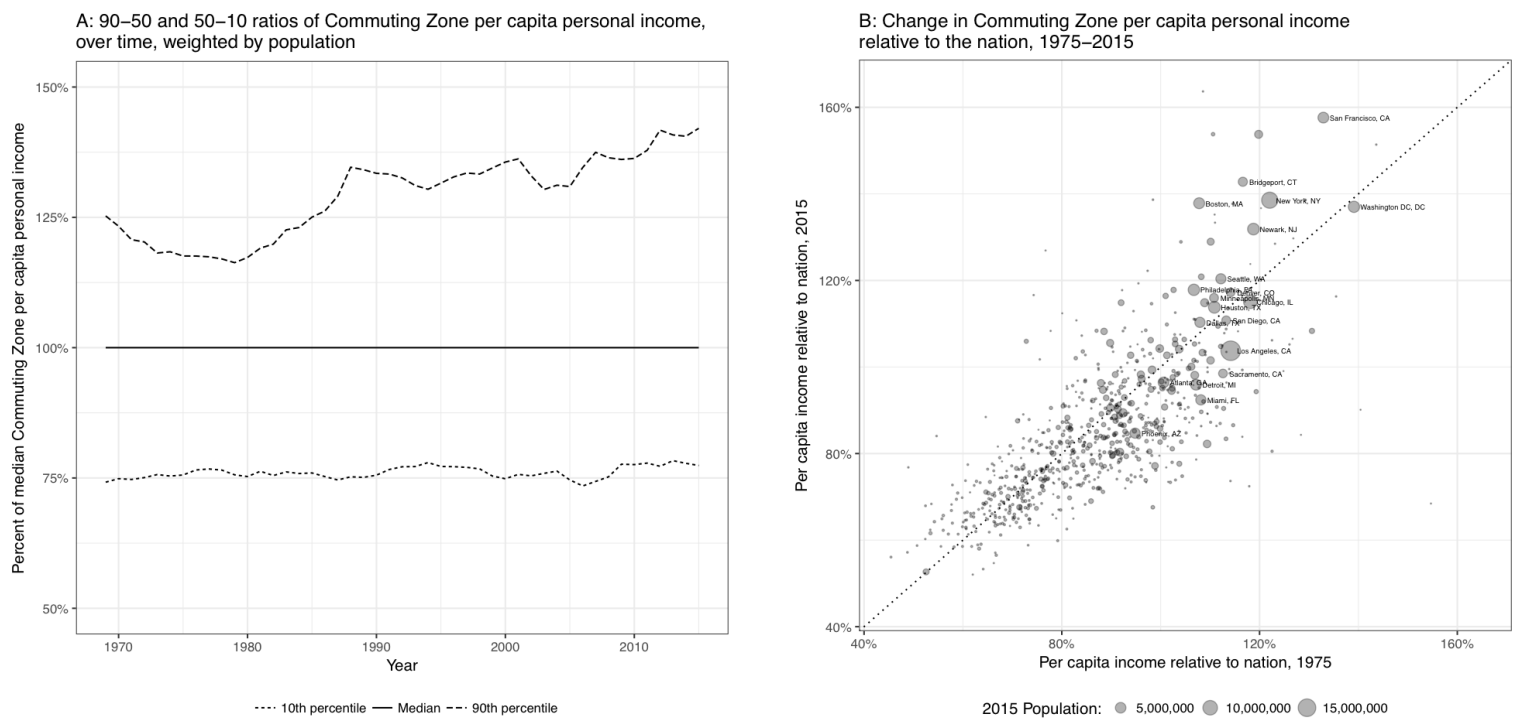

Figure 4: Regional income levels and divergence 


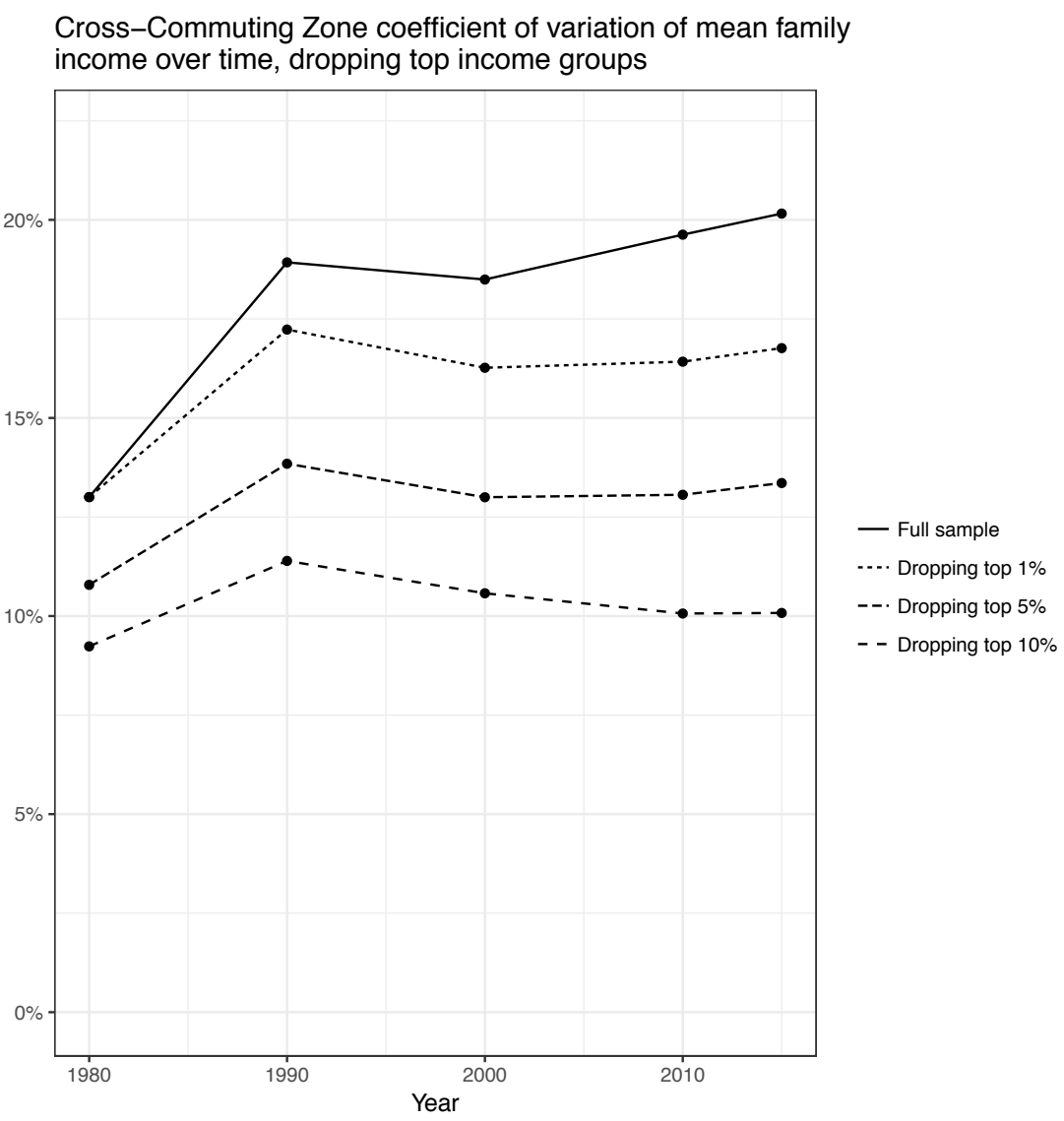

Figure 5: Counterfactual coefficient of variation of mean family income over time by Commuting Zone with various high-income groups removed 


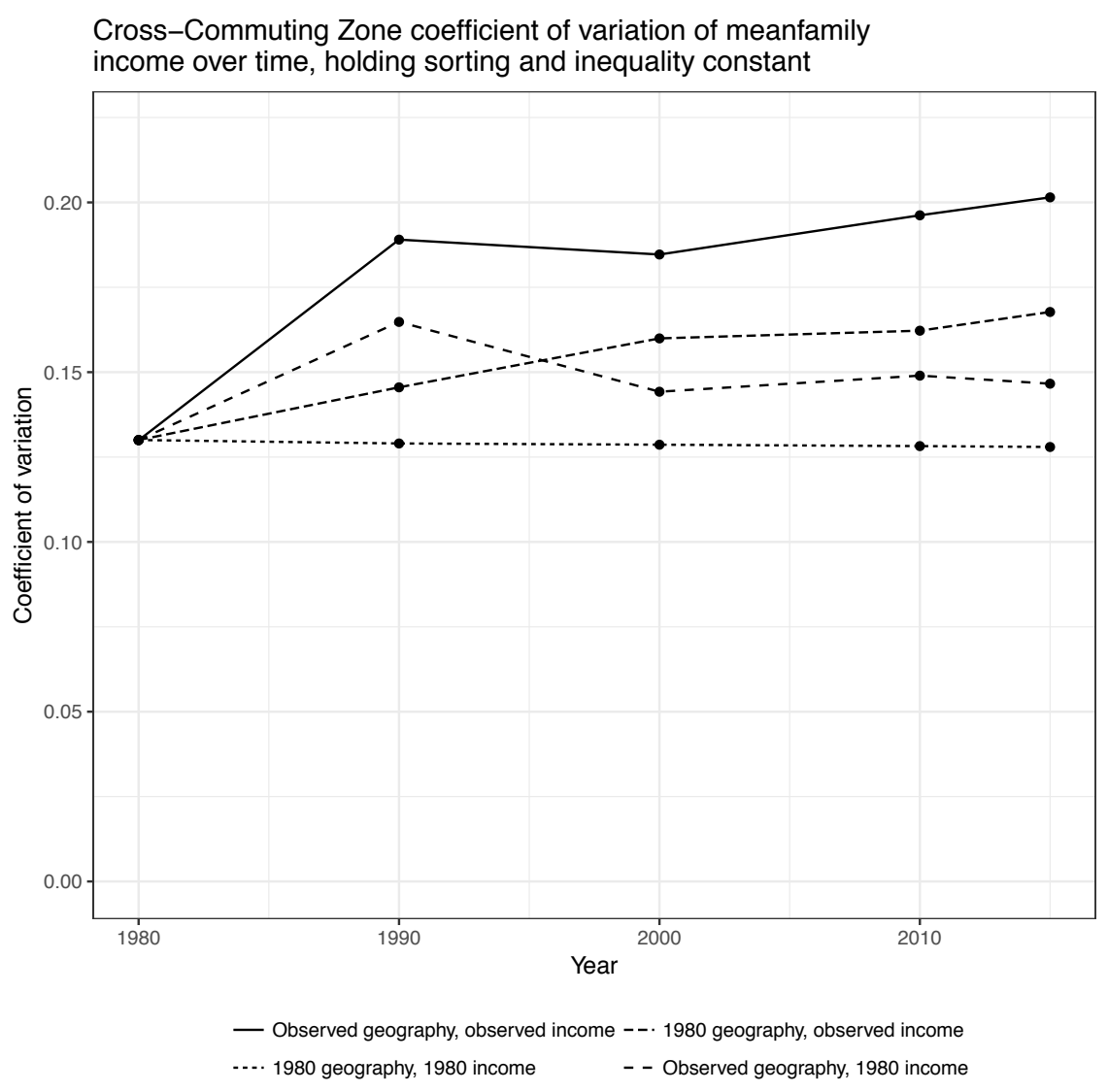

Figure 6: Counterfactual coefficient of variation of mean family income over time by Commuting Zone holding sorting and/or inequality constant 
A: Observed Commuting Zone mean family income relative to nation, 1980
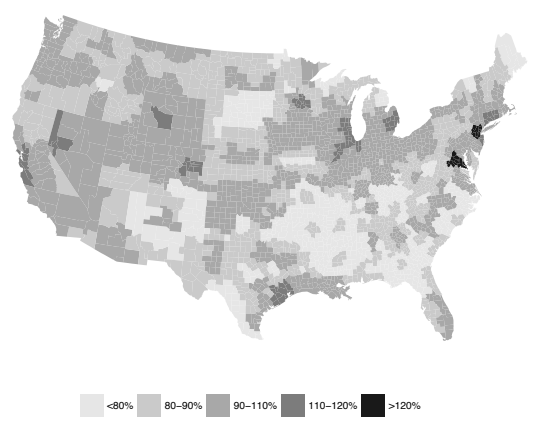

C: Simulated Commuting Zone mean family income
2015 income at each percentile - 1980 geographic distribution

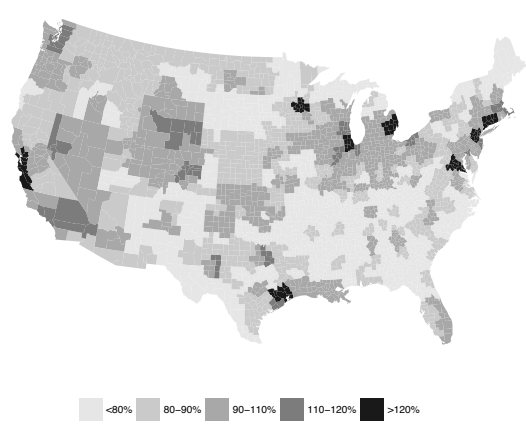

B: Simulated Commuting Zone mean family income
980 income at each percentile - 2015 geographic distribution

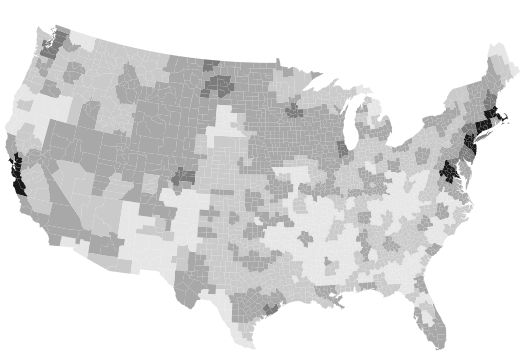

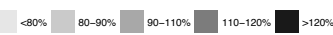

D:Observed Commuting Zone mean family income relative to nation, 2015

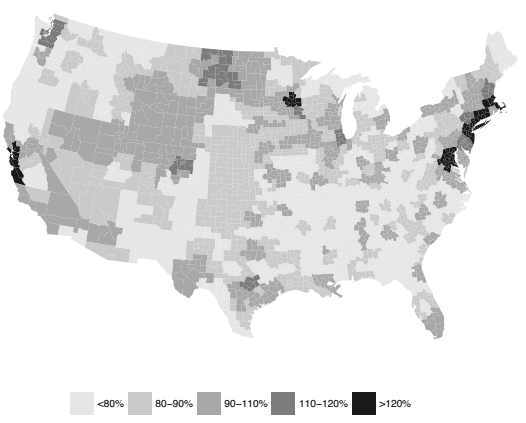

Figure 7: Maps of counterfactual divergence scenarios. (A) Observed mean family income by Commuting Zone in 1980. (B) Counterfactual mean income with income inequality held constant. (C) Counterfactual mean income with income sorting held constant. (D) Observed mean income in 2015. 
Change in alternative measures of income sorting across Commuting Zones over time

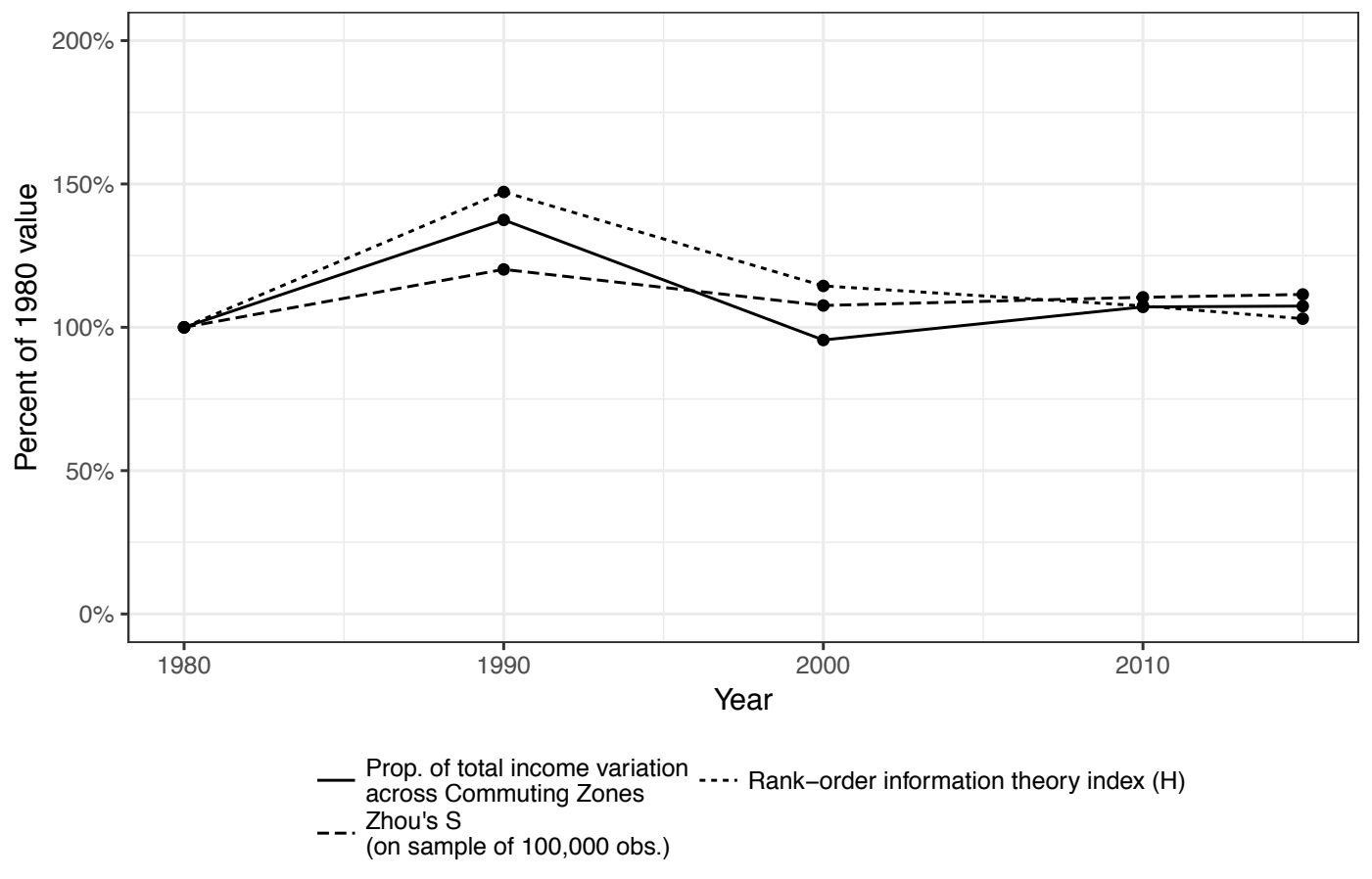

Figure 8: Change in alternative sorting measures over time 


\section{APPENDIX 1: ANALYSIS OF BETA DIVERGENCE}

In this paper I have focused on sigma divergence, measuring the change in cross-sectional variation over time. An alternative approach is to measure beta divergence, the extent to which regional income growth during a period is correlated with income level at the beginning of that period. This approach has been prominent in research on divergence within economics, but suffers from a lack of temporal detail. Here I replicate my main findings using measures of beta divergence rather than sigma divergence.

\section{Observed patterns}

Figure A1 shows beta divergence among Commuting Zones from 1980-2015, using per capital personal income from the BEA data in Panel A and mean family income from the Census in Panel B. The $\mathrm{x}$ axis shows income in 1980 (normalized to 2015 dollars using the CPI-U-RS) while the y-axis shows the real annualized income growth rate from 1980-2015. Each dot represents one Commuting Zone, with size proportional to 1980 population. The dashed lines are regression lines weighted by population. A positive slope on the line indicates that growth from 1980-2015 was positively correlated with income in 1980, meaning that regions diverged during this period. A negative slope indicates regional convergence - that poor regions caught up to rich ones.
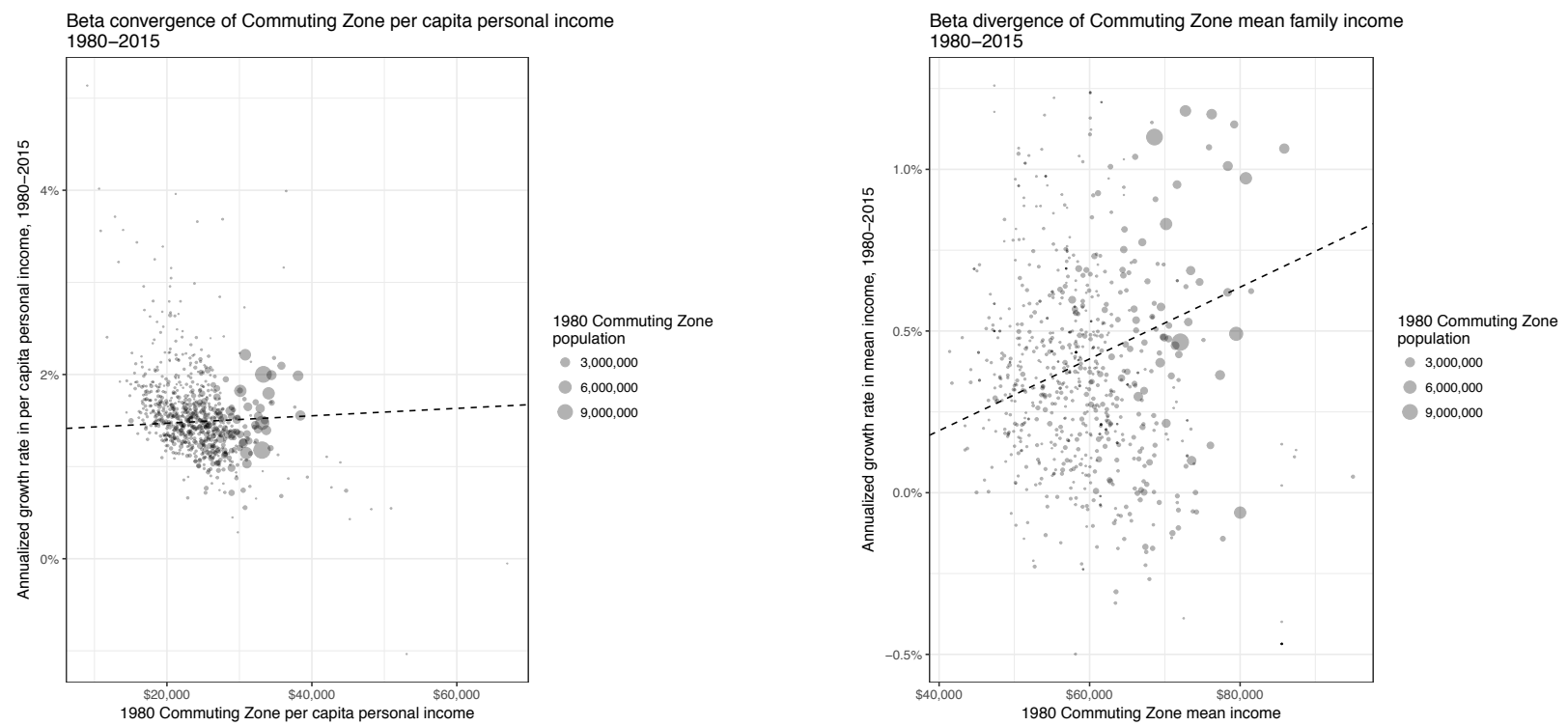

Figure A1. Beta divergence across Commuting Zones in per capital personal income (A) and mean family income (B), 1980-2015.

Panel A shows that in per capita income there was very little convergence or divergence from 1980-2015. Regional income growth had almost no correlation with income level at the start of the period. Panel B, however, shows that in mean family income there was substantial divergence during this time. 


\section{Divergence and the top of the income distribution}

I next turn to the question of whether divergence is driven more by the rich surging ahead or the poor falling behind. Here I calculate beta divergence after first removing the richest $1 \%, 5 \%$, and $10 \%$ of families from the sample. The results are shown in Figure A2. While there was a strong trend of divergence in mean family income among the full IPUMS sample, this trend moderates substantially once the richest few percent of families are removed. Merely dropping the richest $1 \%$ of families drops the slope by more than half (Panel A), while removing the top $5 \%$ of families results in a slope that is almost perfectly flat (Panel B). Among the bottom $90 \%$ of families there was convergence in incomes across Commuting Zones during this time (Panel C).
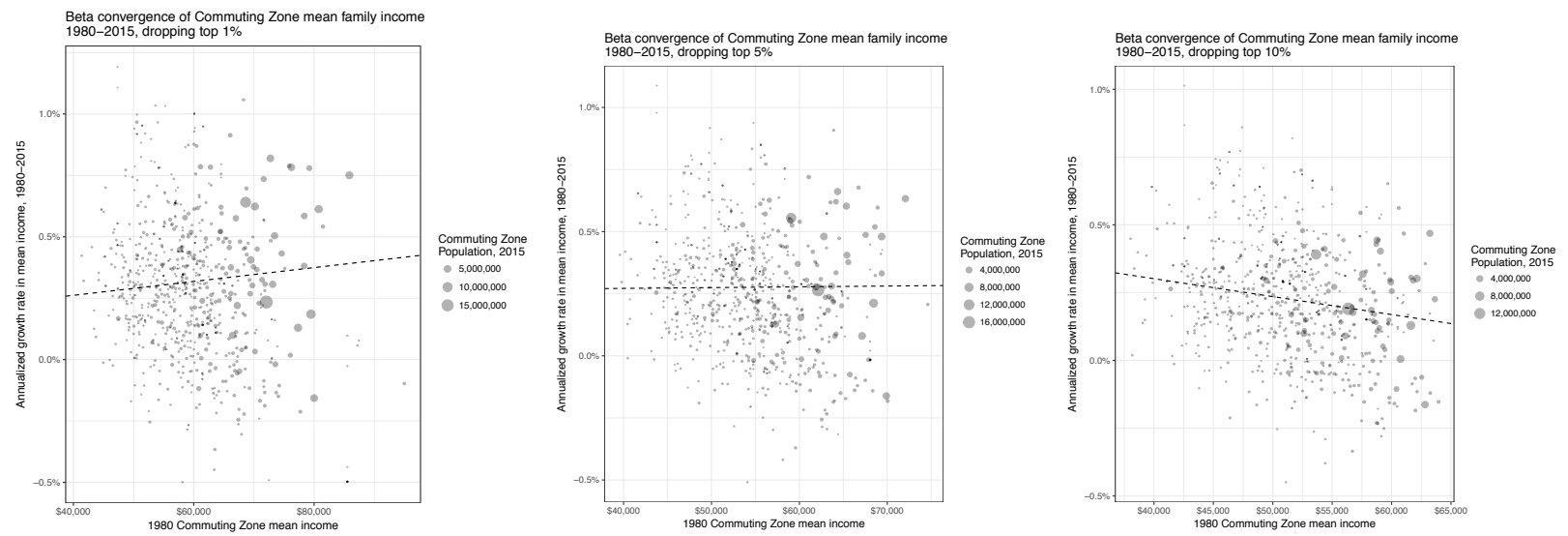

Figure A2. Simulated beta divergence in family income across Commuting Zones, 19802015 , dropping richest $1 \%(\mathrm{~A}), 5 \%(\mathrm{~B})$, and $10 \%(\mathrm{C})$ of families.

Sorting and inequality as contributors to regional economic divergence

Finally I replicate my analysis of the relative importance of sorting and inequality as drivers of regional divergence. I create counterfactual income distributions for each Commuting Zone using the technique described in the main text, but here I compute the counterfactual beta divergence measures by comparing observed income in 1980 to the simulated income growth from 1980-2015 in each scenario.

Panel A of Figure A3 shows what beta divergence would have been had inequality remained at its 1980 level. If there had been no rise in inequality, sorting alone would have resulted in regional convergence, not divergence. This is because there was a certain amount of regional shuffling in income rank during this time. Combining Figure A3A with the "observed geography, 1980 income" line in Figure 7 of the text, we can say that income sorting alone would have resulted in a moderate increase in the amount of dispersion across Commuting Zones from 1980-2015, but that many of the cities that had high incomes at the end of the period would have been different from those who were prosperous at the beginning of the period. This can be seen by comparing the maps in Panels $\mathrm{C}$ and $\mathrm{D}$ of Figure 8 in the main text. If there had been no sorting, Chicago, Detroit, and Houston would rank among the richest cities in the country, while Boston would be far behind. 

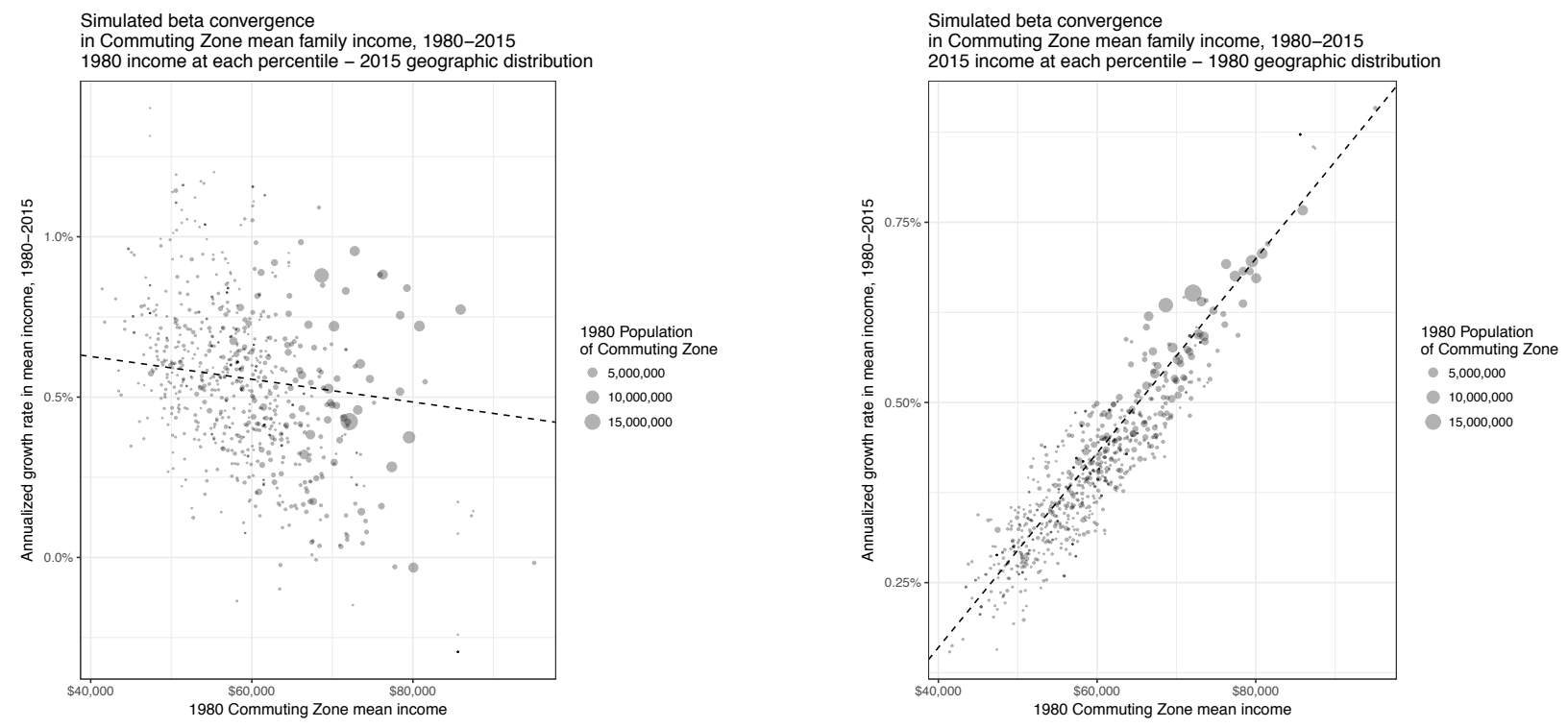

Figure A3. Simulated beta divergence in family income across Commuting Zones, 19802015, with inequality (A) and sorting (B) held constant.

As shown in Panel B, however, the moderately converging effect of income sorting was more than negated by the strong diverging effect of rising inequality. If there had been no sorting, there would have been an almost perfect positive correlation between Commuting Zone mean family income in 1980 and growth in that measure from 1980-2015. This makes sense because without any changes to the geography of which income percentiles are found where, the only change during this time would have been income growth that was strongly correlated with income percentile. 